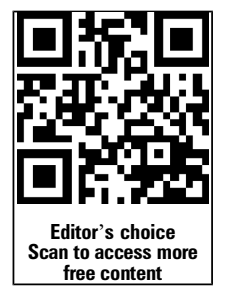

${ }^{1}$ University College London Medical School, London, UK ${ }^{2}$ Shared Services, Health Education England, London Region, London, UK

Correspondence to Dr Deborah Gill, University College London Medical School, 74 Huntley St, London WC1E 6AU, UK deborah.gill@ucl.ac.uk

Received 1 June 2013 Revised 8 August 2014 Accepted 9 August 2014 Published Online First 1 September 2014

\title{
Fostering professionalism among doctors: the role of workplace discussion groups
}

\author{
Deborah Gill, ${ }^{1}$ Ann Griffin, ${ }^{1}$ John Launer ${ }^{2}$
}

\begin{abstract}
Background The professionalism of doctors has come in for increasing scrutiny and discussion, within the profession and in society. Professionalism has also become of central interest in undergraduate and postgraduate medical education. There is a great deal of debate about the nature of medical professionalism, how to promote it and what approaches to learning are most effective.

Objective This study aims to identify the role of workplace-based discussion groups in encouraging and supporting the development of professionalism among doctors.
\end{abstract}

Methods Workplace-based discussion groups including doctors from all non-consultant grades and specialties were established in five hospitals over a 6 month period in 2010-2011. A mixed-methods approach was used to identify the perceived impact of these groups on participants, which included interviewing the group facilitators and education leaders at participating hospitals.

Results Understanding of professionalism at an individual level was improved along with an increased awareness of the collective nature of professionalism in everyday clinical practice. Key to the success of the groups was the creation of a legitimate space to explore professionalism and professional challenges and the use of experienced facilitators who could build trust in the groups. Conclusions A purely individualistic approach to professionalism does not resonate with contemporary, team-based healthcare. Work-based groups can provide a focus for an approach to professionalism that is mindful of self, the team, the culture and the organisation. This evaluation provides guidance to a range of stakeholders on how to develop educational interventions that foster professionalism, personal and collective, and offers some pointers towards the range of factors that may impact on the outcomes of such activities.

\section{INTRODUCTION}

Professionalism is a key component of ethical and effective patient care. It is also increasingly under the public and political spotlight. Development as a professional is a central concern of medical educators. There has been much debate in educational and policy literature about what constitutes medical professionalism and professional action in the 21st century, ${ }^{1-3}$ how learning opportunities in this domain should be provided, ${ }^{4}$ and how attainment should be measured. ${ }^{5}$ However, there have been few tangible solutions to providing effective learning intervention in this domain. ${ }^{6}$

Many of the definitions of professionalism that have emerged over the last three decades have been grounded in 'nostalgic' notions of being professional. These have been accused of "distort (ing) meaningful efforts by medical educators to link medical training with principles and practices of professionalism".7 Understandably, learners have sometimes been cynical about attempts by educators to 'teach' professionalism. ${ }^{8}$

Emerging contemporary notions of professionalism have begun to focus on individual attributes and on an approach to practice that is acquired and sustained individually and collectively as professional values and behaviours are put to work. ${ }^{3} 9$ When viewed in this way, professionalism is a practical rather than theoretical notion that needs to be worked on daily by individuals, teams and organisations $^{10} 11$ and requiring a collective, institutionwide approach to improve patient care. 'Being professional' therefore involves behaviours, values, actions and interpersonal skills and operates at individual, interpersonal and societal levels. ${ }^{5}$ Effective educational interventions to promote professional development are likely to focus on more than one of these aspects and levels. Educational approaches that support 'professionalism in action', 3 nurture professional practices within organisations and promote positive organisational cultures may be a new focus for learning and promoting contemporary professionalism.

An education intervention, undertaken by the London Deanery, introduced hospital-based discussion groups aimed at promoting professionalism, reflective practice and patient-centred care among doctors in training in London. At the time of the intervention, the London Deanery was the organisation overseeing all postgraduate medical education in London. This evaluation aimed to explore the impact of these groups on participants and organisations addressing the following question: What is the perceived impact of work-based discussion groups on the development of professionalism among doctors? This paper describes the evaluation outcomes, and identifies the ways in which such discussion groups might contribute to inculcating professional behaviour within individuals and organisations, and hence improve patient care.

\section{METHODS \\ The intervention}

In 2010-2011, the London Deanery organised workbased discussion groups with a focus on professionalism in five hospitals across London (box 1).

\section{The evaluation}

A mixed-methods approach was used to address the research question. A combination of questionnaires, interviews, observations of discussion groups and document analysis of facilitators' reflections were employed to identify the impact of participation in these groups. However, given the 


\section{Box 1 The intervention: work-based discussion groups}

The work-based discussion groups

Aims: to provide a legitimate place, sometimes called a "pedagogical space", ${ }^{12}$ where talk of professionalism was encouraged and deemed to be valid.

Understanding of professionalism adopted: an approach to work that is acquired and sustained as a result of good modelling, a positive organisational culture, and the informal curriculum ${ }^{13-15}$ and an acknowledgment that while individual clinicians need to take responsibility for their own professionalism, attitudes and behaviours are also affected by the local setting and social contexts.

Methods: Each group was run by a trained and experienced facilitator. A principle for the discussion was to recognise and disseminate success, using an approach derived from Appreciative Inquiry. ${ }^{16} 17$ In a typical session, one or two participants were encouraged to talk about their own experience of their professional work, using specific examples of encounters with patients and colleagues. Fellow participants were encouraged to challenge, question and encourage their colleagues to think about how the dilemmas or opportunities presented were affected by their working contexts, and how they might influence these to create preferred outcomes. Groups met monthly for 90 minutes during the working day in protected time for 6 months.

Group participants: up to 12 non-consultant grade doctors from a range of specialties. All participants were volunteers recruited by open invitation by their director of medical education (DME). The activity was acknowledged as part of the continuing professional development activities provided by the hospital and participants were offered certificates of attendance and the opportunity to continue to develop as a 'professionalism advocate' within the organisation on completion of the programme.

complex and subjective nature of the research question, the generation of qualitative data through interviews was foregrounded with the aim of providing rich data on the personal meaning and learning acquired through participation.

\section{Sampling}

All participants were invited to take part in the study. A purposive sampling frame was applied to those who volunteered for interview to ensure the broadest range of demographics, experience and work-setting characteristics among interviewees. The sample included participants who had stopped attending the groups before the 6 months of participation had been completed. See table 1 for details of the interviewees.

\section{Data generation}

Questionnaires

A questionnaire containing a mixture of free-text and quantitative items was used before and after 6 months of participation. Participants were asked to rate on a 10-point scale where they felt they were in relation to statements concerning their: understanding the nature of professionalism; desire to improve their professionalism; need to further develop professionalism confidence that there will be positive change in their professionalism through participation and in future capacity to influence change in others' professionalism.
Table 1 Details of participants taking part in interviews

\begin{tabular}{|c|c|c|c|}
\hline Participants & Characteristics & Role & Comments \\
\hline A & Male, $<30$ & $\begin{array}{l}\text { Specialty trainee } \\
\text { working in a } \\
\text { mental health Trust }\end{array}$ & $\begin{array}{l}\text { Took part in } \\
\text { follow-up interview }\end{array}$ \\
\hline B & Male, $<30$ & Specialty trainee & $\begin{array}{l}\text { Took part in } \\
\text { follow-up interview }\end{array}$ \\
\hline C & Male, $<30$ & $\begin{array}{l}\text { Core medical } \\
\text { trainee }\end{array}$ & \\
\hline D & $\begin{array}{l}\text { Female, between } \\
41 \text { and } 50\end{array}$ & Staff grade & \\
\hline E & $\begin{array}{l}\text { Female, between } \\
41 \text { and } 50\end{array}$ & Specialty trainee & $\begin{array}{l}\text { Took part in } \\
\text { follow-up interview }\end{array}$ \\
\hline $\mathrm{F}$ & $\begin{array}{l}\text { Female, between } \\
31 \text { and } 40\end{array}$ & Staff grade & $\begin{array}{l}\text { Took part in } \\
\text { follow-up interview }\end{array}$ \\
\hline G & $\begin{array}{l}\text { Male, between } \\
31 \text { and } 40\end{array}$ & $\begin{array}{l}\text { Specialty trainee } \\
\text { working in a } \\
\text { mental health Trust }\end{array}$ & \\
\hline H & Female, $>51$ & Staff grade & \\
\hline IWA & Male,$<30$ & Specialty trainee & $\begin{array}{l}\text { Withdrew from the } \\
\text { programme after } 2 \\
\text { sessions }\end{array}$ \\
\hline IWB & Female, $<30$ & Specialty trainee & $\begin{array}{l}\text { Withdrew from the } \\
\text { programme after } 4 \\
\text { sessions }\end{array}$ \\
\hline
\end{tabular}

\section{Interviews}

In order to capture more nuanced and the personal experiences semistructured face-to-face interviews were undertaken. The interviews were conducted in a relatively informal narrative style or 'conversations with a purpose' ${ }^{18}$, to allow the exploration of aspects of the experience and ideas concerning professionalism that are often tacit and unarticulated. Interviews were carried out by members of the evaluation team and took place in the week following completion of the programme. Semistructured follow-up telephone interviews with a subsample of these interviewees were carried out 6 months after their participation in a group.

We also conducted semistructured, face-to-face interviews with all group facilitators and, to explore organisational impact, with the directors of medical education (DMEs) at the participating hospitals. Interviews ranged from $17 \mathrm{~min}$ to $56 \mathrm{~min}$.

This data was used alongside observations of a small number of the groups in action, and a document analysis of the reflective accounts kept by facilitators on the progress of their groups.

The aim of using multiple modes of data generation was not primarily for triangulation purposes but to capture the range of beliefs, experiences and impacts across all participants and also the richer, more contextual data that provides a quality understanding of the how and why of the impact of workplace-based discussion groups.

Table 2 summarises the, source, sample, type and volume of data generated in this study.

\section{Data management and analysis}

Likert scale questionnaire data was managed in a simple Excel spreadsheet. Median scores for each of the quantitative items were calculated for prequestionnaires and postquestionnaires. Mann-Whitney $U$ tests were used to analyse the differences between preanswers and postanswers to the four items both questionnaires had in common. Where the same participants completed both questionnaires a Wilcoxon signed rank test was 
Table 2 Summary of data

\begin{tabular}{|c|c|c|c|}
\hline Data source & Sample & Data collected & $\begin{array}{l}\text { Code for data } \\
\text { source used in } \\
\text { the results section }\end{array}$ \\
\hline Preparticipation questionnaires & All participants who initially joined groups $(n=56)$ & $\begin{array}{l}43 \text { completed } \\
\text { questionnaires }\end{array}$ & Q1 \\
\hline Postparticipation questionnaire & All participants who remained participants for 6 months $(n=47)$ & $\begin{array}{l}24 \text { completed } \\
\text { questionnaires }\end{array}$ & Q2 \\
\hline $\begin{array}{l}\text { Interviews with participants at the end of } 6 \\
\text { months }\end{array}$ & Sampling frame used to generate eight potential interviewees & eight interviews & $I^{1} A-H$ \\
\hline $\begin{array}{l}\text { Interviews with those who withdrew from the } \\
\text { groups }\end{array}$ & Sampling frame used to generate four potential interviewees & two interviews & IWA and IWB \\
\hline $\begin{array}{l}\text { Follow-up interviews } 6 \text { months } \\
\text { postparticipation }\end{array}$ & $\begin{array}{l}\text { Purposive sample of all initial interviewees to generate four potential } \\
\text { interviewees }\end{array}$ & four interviews & $\mathrm{IP}^{2} \mathrm{~A}, \mathrm{~B}, \mathrm{E}$ and $\mathrm{F}$ \\
\hline $\begin{array}{l}\text { Interviews with facilitators at the end of } 6 \\
\text { months }\end{array}$ & All group facilitators $(n=5)$ & five interviews & IF A-E \\
\hline Interviews with DMEs at the end of the pilot & All DMEs (or acting representatives) at participating hospitals $(n=5)$ & five interviews & IDME A-E \\
\hline Observations of groups & Sampling of three of the five groups & three observations & $01-3$ \\
\hline $\begin{array}{l}\text { Reflective accounts by facilitators following } \\
\text { meetings }\end{array}$ & All group facilitators & 22 submitted & R 1-22 \\
\hline
\end{tabular}

used to compare the preparticipation and postparticipation results.

The interviews were audio-taped and transcribed verbatim by a professional stenographer. Interview field notes were used to support the analysis of interview data. Detailed observation notes, facilitators' reflective notes, and questionnaire-free text data were also part of the data set. The data management package QSR NVivo 10 was used to manage and organise all of the qualitative data.

Given the complex nature of the research questions and the multilayered tools used to address this, the qualitative data from interviews, free text in questionnaires, reflective documents and observations were considered as a single data set. The approach to analysis of the qualitative data was thematic analysis: this was inductive, allowing meaning to emerge from the data; and deductive, to answer the questions posed by the study. ${ }^{19}$ Initial themes for coding the data were generated from the research questions, and further interpretation generated other themes and constructs which were produced iteratively by engaging and re-engaging with the data. Thematic analysis of the data set was undertaken by two senior research staff independently and tentative codes and themes presented at the research progress meetings. Coding themes were then discussed and refined, and a final coding framework was agreed upon and then applied to the entire qualitative data set.

\section{Ethical approval}

The evaluation was conducted in line with British Educational Research Association guidelines ${ }^{20}$ and the study was deemed a service evaluation and exempted from formal ethics approval by the Chair of the local National Health Service (NHS) Research Ethics committee.

\section{RESULTS}

\section{Demographics}

Fifty-six doctors initially took part in discussion groups (26 men and 30 women) and 47 completed the full period of 6 months. They came from a very wide range of specialties and their posts ranged from 1st year core trainees to staff grades with many years' experience. The majority were in middle grade training positions.

\section{Numerical questionnaire data}

Seventy-seven per cent of participants (43/56) completed a preparticipation questionnaire and 24 of the 47 doctors who completed the programme completed a postparticipation questionnaire (51\%). Twelve participants provided prequestionnaire and postquestionnaire responses and gave their names, allowing their preresponses and postresponses to be linked (27\%).

Participants' self-rated understanding of professionalism post participation was higher than it had been pre participation (median preparticipation $=6$; range $3-8$; median postparticipation $=8$; range 5-9). This change was statistically significant $(\mathrm{z}=-5.8 ; \mathrm{p}<0.001)$. For the 12 participants who completed preparticipation and postparticipation questionnaires, there was a statistically significant increase of two points in their self-rated understanding of professionalism $(\mathrm{z}=-2.9 ; 0.003)$. There were no other statistically significant changes.

\section{Qualitative data set}

The following five broad themes emerged from across the data set and concerned: the impact of participation, understanding professionalism, the impact of stories, challenges to professionalism and sustaining change.

\section{The impact of participation}

Although the focus was on professionalism, the benefits of joining and participating in these groups seemed to arise almost irrespective of the content: sharing stories of the workplace was seen by participants as a productive activity in itself.

Within the groups, the freedom to speak, the flattening of hierarchies, the potential for professional socialisation and the opportunity to discuss important issues with a supportive peer group were all seen as important benefits of membership.

...It was good for so many reasons: I became closer to other doctors in the hospital, I had the opportunity to discuss in depth... issues that affect all of us and it made me think of times I just thought were work but where in fact I had an influence. $\left(\mathrm{IP}^{1} \mathrm{D}\right)$

The groups were called 'Trust-based' groups because they took place in NHS hospital Trusts. However, one of the groups 
started to call their group a trust based group: a group where trust was fostered and its benefits maximised for really getting to the 'nitty-gritty' of experience and learning from it. (O3).

Participation in the group was described by more than one facilitator as a 'dress rehearsal': a space in which to practise favourable responses to challenges to professionalism, as well as a place to benchmark one's own unique perspectives (R1\&9).

\section{Understanding professionalism}

Interview data, the free text sections of questionnaires and facilitator interviews, all indicated that participation seemed to result in language shifting from somewhat hackneyed and inward facing signifiers of professionalism to understandings that showed an increasing awareness of the complexity of professionalism and professional actions:

\begin{abstract}
...to start off with I guess I would have thought, you know, well [professionalism] is putting the best interests of your patients first and being committed to your job and not doing anything to put people in danger. But I guess now my understanding's a lot broader ... it's not just about patients, it's about the way you communicate with your colleagues. $\left(\mathrm{IP}^{2} \mathrm{~F}\right)$
\end{abstract}

The interaction between the context (the organisation) and professionalism was a recurrent theme of these groups, with participants talking about professionalism in this light:

(we) spoke about ... organisational structure and more of the team structures and how professionalism impacts on that, where you as an individual, how you can use your abilities and skills to improve things in a wider perspective. .... [The course] made me think about how to develop things as I go through my training and developing into a consultant, how I can think about that within organisations as well, rather than just at an individual level. (IP $\left.{ }^{1} \mathrm{~B}\right)$

Following participation, broader definitions of professionalism were offered. These tended to encompass the role of others, perhaps signifying a conceptual shift in understanding of professionalism as not an act of the individual, but as a construct that is socially mediated within the workplace:

The Professionalism Project helped me gain more...identify more with my job, with my position in the hospital and I decided I was representing not just myself, that's right, yeah, but the whole of the establishment really. I was also part of the establishment. (IP $\left.{ }^{1} \mathrm{D}\right)$

\section{The 'storying' of professionalism}

The sharing of stories about professionalism provided the impetus to explore the effects of actions and inactions, and an opportunity for individuals to unpick perceived influencing behaviours on others. With the help of group members, this allowed an exploration of alternative perspectives and possible alternative outcomes.

Participants reflected that while clinical conversations are likely to happen naturally every day, talk about professionalism is more problematic in the working day environment. As anticipated, the participants used the groups as "pedagogical spaces" to discuss professionalism. Group membership gave legitimacy to its exploration:

If you said I'm going to set something up or I want to start this and there's no accreditation and there's no certificate it's just not going to happen... The benefit for the group was it had institutional backing and it had protected time ... it's not something you can do over coffee and it was helpful to have people from different specialties and different grades... Certainly my experience has been that when I've tried to initiate discussions around these points it doesn't quite work. The forum of having people there for that particular purpose seemed to be one think that made it work pretty much. $\left(\mathrm{IP}^{1} \mathrm{~B}\right)$

Participation through the use of stories had a meaningful effect on participants in a range of different ways. Some facilitators suggested conversation and shared story-telling heightened participants' awareness of professionalism as it is acted out in their work settings. For some participants it created a growing confidence to explore situations that they would have previously ignored:

Everyone told stories within that group, irrespective of their grade or seniority, and they all showed themselves to be vulnerable, they all showed themselves to be struggling, they all showed themselves to be problem solving. (IF C)

\section{Challenges to professionalism}

Interviews with doctors and the DMEs revealed a range of social and structural barriers to professionalism. Both of these groups saw the pressure of service delivery and the way in which the healthcare is currently organised as barriers to exhibiting and developing professionalism. Factors here included the transient nature of hospital allegiance for doctors in training, the multiple ways in which hospitals create barriers to developing a sense of belonging and the fragmentation of the workplace and delivery teams, which inhibits opportunities to learn professionalism with and through relationships with fellow professionals:

Unfortunately medicine is still very hierarchical and changes generally have to come from the top down, it's very difficult to influence things from the bottom up..... (IP $\left.{ }^{1} \mathrm{~A}\right)$

And you talk to the trainees and you realise they see very little of their senior colleagues...And now I think we have trainees sort of wandering around a hospital being berated by all and sundry for things that aren't happening and things they're not responsible for. (IDME A)

\section{Creating enduring change}

One of the proposals made by the London Deanery was that participants in these groups, working with the DME, could become 'professionalism advocates' within their hospital following involvement in the programme. While the Deanery and DMEs were hopeful of the influencing effect on others of group participants, most of the participants did not share these hopes. Being an advocate was not seen as an easy role, nor one that could be done effectively without support and mentoring. Traditional role hierarchies and a lack of influencing power were seen as barriers, while the transient nature of a junior doctor's association with a hospital and the looseness of their allegiance were again seen as a barrier:

My only concern about actually naming the advocate to everyone in the beginning, .... is that there's a worry that [the advocate] might make a mistake, you know. No one is perfect... we also can make mistakes so I'm not sure...it's a big responsibility being known as the advocate for professionalism for the hospital, you know. (IP $\left.{ }^{1} \mathrm{D}\right)$

However group participants and DMEs did see the potential value of such groups as a way for organisations to build professionalism into the development of their healthcare workers and teams:

The Trust could do [a group focusing on professionalism] as a part of an away-day for teams that are struggling or maybe where there's been teams where the feedback from the patient surveys 
haven't been so good. Instead of as a punishment to say 'Oh your team's rubbish' it could be more of a 'Let's see how we can develop this, let's see how we can improve things with this sort of work. (IP $\left.{ }^{2} \mathrm{~B}\right)$

I suppose having facilitated groups like the one $\mathrm{xxx}$ ran was invaluable. So maybe having more of those sort of events.....I don't think you'd be able to force all of them into that sort of role, but maybe having more opportunities for that. (IDME B)

\section{DISCUSSION}

Participation in work-based discussion groups has a positive effect on understanding of professionalism at an individual level and an increased awareness of the collective nature of professionalism in everyday practice. The impacts appear to be due to the opportunities for frank and trusting interaction with colleagues that they provide and the sharing of workplace stories that in itself is a productive activity. Key to the success of the groups was the creation of a legitimate space to explore professionalism and professional challenges and the use of experienced facilitators who could build trust in the groups.

A purely individualistic approach to professionalism does not resonate with contemporary, team-based healthcare and the definition of professionalism that this intervention adopted, and the pedagogical approaches this encouraged, seems to have promoted a more contemporary understanding of professionalism as an approach to practice and a shared responsibility. This study suggests discussion groups are a way of providing a more engaging, tangible approach to creating learning in this domain. ${ }^{8}$

The benefits of facilitated case-based discussion groups are already well established in primary care and include mutual support and learning, increased reflectiveness and an awareness of how the quality of teamwork can impact on patient care. ${ }^{21}$ Groups focusing on the 'storying' of dilemmas that arise in practice have also been shown to improve support for coworkers and the delivery of compassionate care in palliative care settings. ${ }^{22}$ This study suggests such groups, if well run and supported, have a place in fostering professionalism in secondary care settings.

In the UK, the public inquiry into unnecessary deaths at the Mid Staffordshire Hospitals highlighted many failings of professionalism and professional behaviour among clinicians. In setting out his recommendations, the chairman Robert Francis QC outlined what he saw as the professional expectations for future $^{23}$ : and how healthcare organisations were failing to build a positive culture. ${ }^{24}$ One way we can build such a positive culture is to create legitimate opportunities for healthcare workers to come together, narrate their experiences, learn from one another, 'dress rehearse' challenges and develop new insights into what it means to be professional.

The pressure of service delivery and the way in which it is currently organised are seen as barriers to exhibiting and developing professionalism. These pervasive structural and social barriers suggest that educational interventions like these in isolation, no matter how successful for participants, will create only limited change. However, not all barriers to fostering professionalism are outside the realm of educational influence. Educators need to help shift the paradigm of workplace-based learning away from the acquisition of measurable competencies and knowledge, towards a participatory model more aligned to what is already known about how professional learning occurs. $^{25}$ This study suggests this novel approach of using workbased discussion groups are a step in the right direction and can foster professionalism that is mindful of self, the team, the work, the culture and the organisation.

\section{Limitations of the study and future work}

This study interrogated the outcomes of one well-supported intervention and explored perceived impacts soon after completion of the programme rather than changes in patient outcomes. ${ }^{26}$ Further work should focus on sustainability; how such activities can be embedded in organisations and capturing sustained impacts of such interventions, and the impacts on patient outcomes and patient experiences of such educational efforts to improve professionalism.

\section{Main messages}

Facilitated work-based discussion groups can deepen doctors' understanding of the multidimensional nature of professionalism.

- Protected time and creating a 'learning space' give validity to attempts to foster professionalism.

- Sharing narratives of successes and challenges in professionalism can be a valuable experience.

- Basing discussion groups within hospital ensures a focus on collective professionalism and encourages changes that take account of contextual issues.

\section{Current research questions}

- Do educational strategies designed to improve professionalism make any improvements to patient care and experiences?

- How can structural and service delivery barriers to fostering professionalism be addressed?

- Is there a role for professionalism advocates and how should they operate?

\section{Key references}

- Jones L, Green J. Shifting discourses of professionalism: a case study of general practitioners in the United Kingdom. Sociol Health IIIn 2006:927-50.

- Martimianakis MA, Maniate JM, Hodges BD. Sociological interpretations of professionalism. Med Educ 2009;43: 829-37.

- Clandinin DJ, Cave M-T. Creating pedagogical spaces for developing doctor professional identity. Med Educ 2008;42:765-70.

- Goldstein E, Maestas R, Fryer-Edwards K, et al. Professionalism in medical education: an institutional challenge. Acad Med 2006;81:871-87.

- Cooperrider D, Srivastva S. Appreciative Inquiry in organizational life. Res Organ Change Dev 1987;1:129-69.

Contributors DG was Principal investigator for the evaluation project and was involved in the conception and design of the study. She was involved in the data collection and data analysis, and is the author of the first draft of the submission. She was involved in all further redrafts. AG was involved in the conception and design of the study, data collection and data analysis, and has commented on and contributed to all drafts of the submission. JL was involved in the conception and design of the study, and has commented on and contributed to all drafts of the submission.

Funding This work was supported by funding from the London Deanery. 
Competing interests $J L$ was employed by the London Deanery at the time of this project.

Ethics approval NHS Research Ethics Committee.

Provenance and peer review Not commissioned; externally peer reviewed.

\section{REFERENCES}

1 Swick H. Toward a normative definition of medical professionalism. Acad Med 2000;75:612-16.

2 Royal College of Physicians. Doctors in society: medical professionalism in a changing world. Report of a Working Party of the Royal College of Physicians of London. London: RCP; 2005.

3 General Medical Council. Good medical practice. 4th and 5th edn. London: GMC, 2006 and 2013.

4 Cruess R, Cruess S, Steinert Y, eds. Teaching medical professionalism. Cambridge: Cambridge University Press, 2009.

5 Hodges BD, Ginsberg S, Cruess S, et al. Assessment of professionalism: recommendations from the Ottawa 2010 Conference. Med Teach 2011:33:354-63.

6 Gordon J. Fostering students' personal and professional development in medicine: a new framework for PPD. Med Educ 2003:37:341-9.

7 Hafferty F. Professionalism and the socialisation of medical students. In: Cruess R, Cruess S, Steinert Y, eds. Teaching medical professionalism. Cambridge: Cambridge University Press, 2009:53-70.

8 Birden HH, Usherwood T. They liked it if you said you cried": how medical students perceive the teaching of professionalism. Med J Aust 2013;199:406-9.

9 Jones L, Green J. Shifting discourses of professionalism: a case study of general practitioners in the United Kingdom. Sociol Health IIIn 2006:927-50.

10 Bleakley A. Broadening conceptions of learning in medical education: the message from teamworking. Med Educ 2006:40:150-7.

11 Martimianakis MA, Maniate JM, Hodges BD. Sociological interpretations of professionalism. Med Educ 2009:43:829-37.

12 Clandinin DJ, Cave M-T. Creating pedagogical spaces for developing doctor professional identity. Med Educ 2008;42:765-70.
13 Goldstein E, Maestas R, Fryer-Edwards K, et al. Professionalism in medical education: an institutional challenge. Acad Med 2006;81:871-87.

14 Brater DC. Infusing professionalism into a school of medicine: perspectives from the Dean. Acad Med 2007;82:1094-7.

15 Cottingham $\mathrm{AH}$, Suchman $\mathrm{AL}$, Litzelman DK, et al. Enhancing the informal curriculum of a medical school: a case study in organizational culture change. J Gen Intern Med 2008:23:715-22.

16 Cooperrider D, Srivastva S. Appreciative Inquiry in organizational life. Res Organ Change Dev 1987:1:129-69.

17 Suchman AL, Williamson PR, Litzelman DK, et al. Toward an informal curriculum that teaches professionalism: transforming the social environment of a medical school. J Gen Intern Med 2004;19:501-4.

18 Burgess RG. Conversations with a purpose: the ethnographic interview in educational research. In: Burgess RG, ed. Studies in qualitative methodology: a research annual vol. 1. London: JAI Press, 1988:137-55.

19 Miles M, Huberman A. The qualitative researcher's companion. Thousand Oaks: Sage, 2002

20 British Educational Research Association (BERA). Ethical Guidelines for Educational Research. 2004. http://www.bera.ac.uk/files/guidelines/ethica1.pdf (accessed 21 Mar 2012).

21 Sommers LS, Launer J, eds. Clinical uncertainty in primary care: the challenge of collaborative engagement. London: Springer, 2013.

22 Lown B, Manning C. The Schwartz Center rounds: evaluation of an interdisciplinary approach to enhancing patient-centered communication, teamwork, and provider support. Acad Med 2010;85:1073-81.

23 Francis R. Chairman's report. 2013. http://www.midstaffspublicinquiry.com/sites/ default/files/report/Chairman\%27s\%20statement.pdf (accessed 12 May 2013).

24 Francis R. The Francis report: a second public inquiry into the Mid Staffs NHS Foundation Trust, January 2005-March 2009. 2010. http://www.midstaffsinquiry. com/pressrelease.html (accessed 12 May 2013).

25 Maudsley G, Strivens J. Promoting professional knowledge, experiential learning and critical thinking for medical students. Med Educ 2000;34:535-44.

26 Kirkpatrick DL. Evaluating training programs. 2nd edn. San Francisco, CA: Berrett-Koehler, 1998 